\title{
The application of CFD software in the explosive hazardous area classification
}

\author{
Andrzej Krauze ${ }^{1, *}$ \\ ${ }^{1}$ The Main School of Fire Service, Faculty of Fire Safety Engineering, 52/54 Slowackiego St., 01-629 \\ Warsaw, Poland
}

\begin{abstract}
This article is devoted to the practical application of CFD Computational Fluid Dynamics software, as a tool helpful in the explosive hazardous area classification. The practical examples will be discussed, which show that use of computer software for the simulation of gas emissions or the simulation of vapors of flammable liquids, allows not only visualization, but also improvement the quality of following conclusions received during the explosive hazardous area classification. The Computational Fluid Dynamics is a branch of physics which deals with solving transport equations for given boundary conditions using numerical methods. The solution is found by dividing the analyzed space into a specified number of small control volumes (cells). At the same time, time period is divided into short steps. Then, for each of the cells at each time step, the transport equations are converted into the system of linear equations. Such systems are solved using appropriate numerical algorithms.
\end{abstract}

\section{Introduction}

Thanks to the use of computer programs, it's possible to model a wide range of phenomena, such as releases and dispersion of hazardous substances, smoke of buildings, development of fires and the effects of explosions [1,2]. Imaging of this type of phenomena is accompanied by the creation of fire scenarios for the needs of expert reports, safety reports, and operational and rescue plans.

The aim of the article is to approximate the phenomena associated with the emission of gases / vapors of flammable liquids for the purposes of the explosive hazardous area classification. The results of simulation of vapors and gases of flammable liquids will among others, visualized ranges and shapes of the explosion hazard zones, determination for explosive concentration of mixtures at any point as a function of time, taking into account the influence of ventilation systems, inside and outside the buildings and estimation of the mass of substance that persists in ambient conditions after stabilization of outflow conditions. Thanks to the wide possibilities of the software, it is possible to carry out simulations related to emissions of substances from the tank, pipeline as a result of leaks or evaporation from the backwaters, as well as gas emission from blow-off valves. The

\footnotetext{
* Corresponding author: akrauze@sgsp.edu.pl
} 
programs enable modeling of the dispersion, taking into account the coefficient $d_{p}$ - the weight of gas relative to air, which allows to illustrate how the substance will spread in relation to the source of emission.

In the field of entering input data, modern programs allow to determine a large number of initial parameters. For release this will be, for example, the initial temperature, while for dispersion - wind speed and direction, temperature, pressure, humidity, as well as the exact geometry of terrain (including relief and cover, i.e. also with the possibility of entering specific buildings, hills or depressions). CFD computer programs are tools widely used in assessing the efficiency of residential and emergency ventilation, which is of great importance when correctly positioning and setting the thresholds of explosion.

As a result of the simulation, the time of activation of detectors, the concentration distribution of combustible substances in space as a function of time and airflow in the room are obtained. This allows dimensioning of explosive hazardous areas, evaluation of the correct placement of the supply air diffusers and exhaust grilles and qualification of ventilation efficiency.

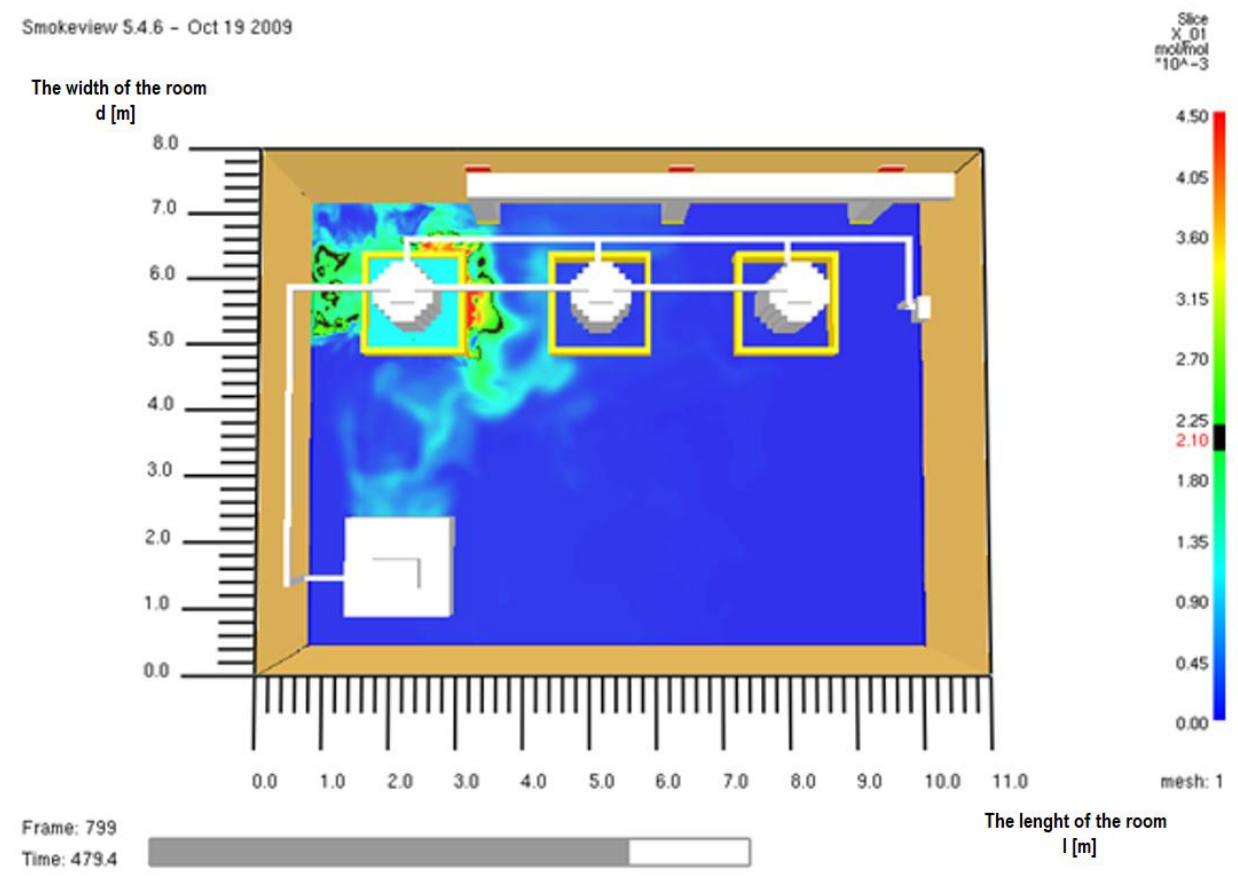

Fig. 1. Example of determining the distribution of acetone vapor concentrations at a height of $10 \mathrm{~cm}$ in the production room after emergency release with operating ventilation. 
The PN-EN 60079-10-1: 2016-02 [3] standard concerns to CFD software as a useful tool to determine:

- the influence of ventilation on the dispersion of gases / vapors of flammable liquids (chapter 5.2),

- the extent of the gas cloud / flammable liquid vapor (Annex C 3.1 and D 3),

- the time of maintaining explosive concentrations after emission decay (Annex C 3.1),

- the efficiency of ventilation in different parts of the same room - with high accuracy (Annex C 3.4),

- the impact of complex technological installations in the open air on the movement of the gas cloud / flammable liquid vapors (Annex C 3.4),

- the impact of atmospheric pressure factors on gravitational ventilation in the building, and thus on the dispersion of gases / flammable liquids vapors in closed rooms (Annex C 5.2).

However, it was noted that the use of tools should take into account software limitations and well-thought-out insertion of input data in order to obtain the most similar values to the real ones.

One of the most popular CFD programs in the fire safety engineering community, is Fire Dynamics Simulator (FDS) - created and developed by NIST (National Institute of Standards and Technology). This program, associated primarily with fire modeling, is also used for research into gas and vapor dispersion. The carried out the experimental work $[4,5,6]$ showed satisfactory accuracy (error within the limits 10-20\%) in determining concentrations of substances in rooms. The dispersion of methane, propane, hydrogen and gasoline vapors was tested. The main factor affecting the exact modeling results is the turbulence model - LES Smagorinsky - Lilly [7]. This model allows for a detailed reflection of gas turbulent mixing processes (mixing with air) and, unlike RANS models (i.e. The K-epsilon), using averages values in time, a more accurate determination of instantaneous concentrations of substances. Modeling of gas dispersions using FDS, however, requires special attention not only on the size of the calculation grid, but also the constants: Schmidt and Smagorinsky [7], which in the case of dispersion modeling require setting different values than in the case of fires. An important factor is the correct introduction of the substance emission intensity. Since FDS does not allow modeling of liquid evaporation or outflow of pressurized gas, these values (as a function of time) should be determined using a different model and entered as input data.

For the LES (Large Eddy Simulation) model, the size of the grid cells determines the accuracy of the solution. Smaller cells result in increased accuracy, but at the same time lengthen the solve time. The results of the simulation were obtained in the form of isosurface for specific volume concentrations of methane. The views were generated in the Smokeview application [8], used to visualize the results obtained by FDS program.

\section{Practical use of dispersion simulation for the explosive hazardous area classification}

Comparative analysis consisted in verification of results obtained using traditional calculation methods using the formulas contained in PN-EN 60079-10-1: 2016-02 Explosive atmospheres - Part 10-1: Classification of areas -- Explosive gas atmospheres [3] and according to the guidelines of the Chamber of the Natural Gas Industry "Technical standard ST-IIG-0401: 2015 The Gas Network. Explosive hazardous areas - assessment and determination" [9] with simulation results for the same case using Computational Fluid Dynamics (CFD). In the final stage, the results were compared and the appropriate 
conclusions were drawn. The analysis referred to scenario related to natural gas emissions, taking into account the following conditions:

- the jet diffusion from the outlet openings of bleed pipes of equipment such as block valve stations, safety relief valves, air-vent valves and a drain-off function, dehumidifiers, filters, separator, etc., where the outflow velocity from the emission source is high and the diffusion from the emission sources occurs deliberately, as a rule of result of operation activities;

- the turbulent dispersion, which may occur under normal operating conditions in slot of flange joints, threaded joints, clamp joints, reducer housings and pressure regulators, i.e. where dispersion from the emission source occurs accidentally, as a rule of result of poor equipment design.

\subsection{Emission during blowdown process from safety valve}

On the basis of calculations carried out in accordance with the ST-IGG-0401:2015 Technical Standard [9], the range of the zone for blowdown emissions was obtained. Considered case concerns emissions from the directed upward safety valve from the reducing and metering station. Methane emission at $0.64 \mathrm{~kg} / \mathrm{sec}$ in outdoor air. Pressure of 4.25 bar, valve diameter of $\mathrm{DN} \mathrm{32}$, time: $65 \mathrm{~s}$. The release in the simulation shall be between 5 and 70 seconds (time from the start of the release).

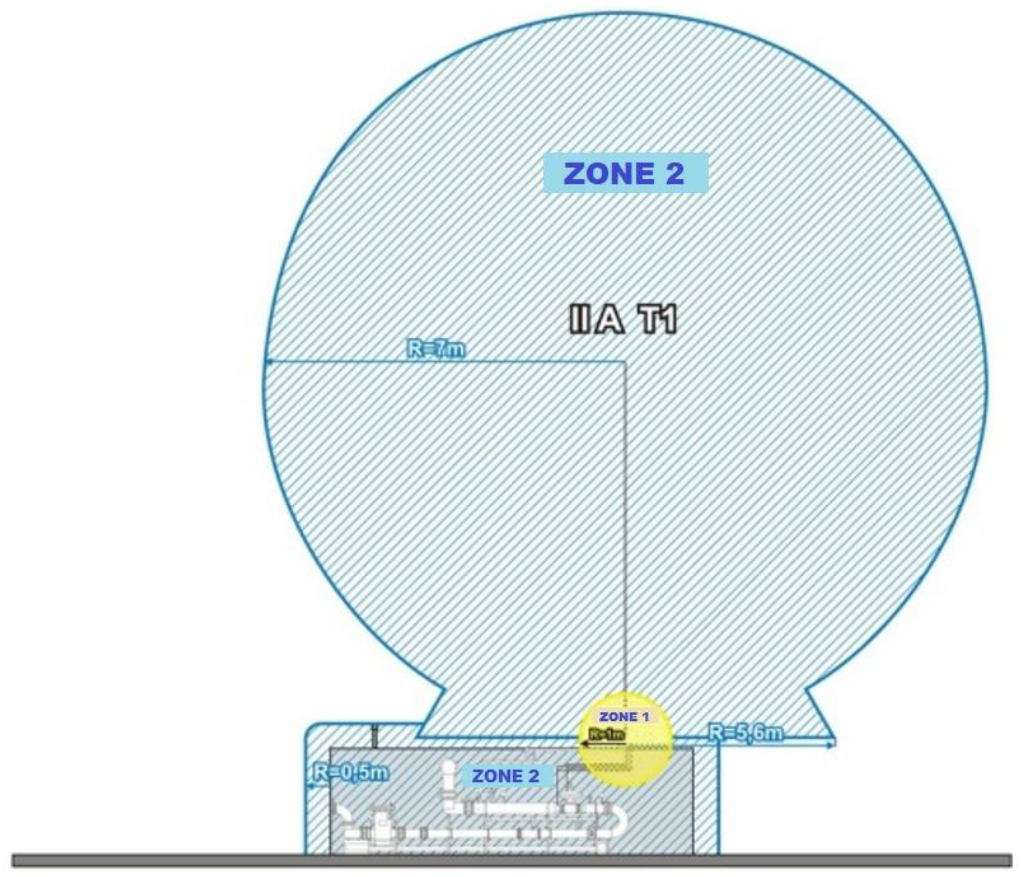

Fig. 2. Diagram of configuration of explosive hazardous areas around relief valves for the natural gas diffusion (pressure of 4.25 bar DN 32). View from the side of the container. 
Table 1. Results of calculations according to Technical Standard ST-IGG-0401:2015.

\begin{tabular}{|c|c|c|c|}
\hline $\begin{array}{c}\text { Pressure on } \\
\text { the natural } \\
\text { gas }\end{array}$ & $\begin{array}{c}\text { Setting of } \\
\text { safety valve } \\
{[\mathbf{M P a}]}\end{array}$ & \multicolumn{2}{|c|}{ Radius of zone 2[m] } \\
\cline { 3 - 4 } & & $\begin{array}{c}\text { Sphere } \\
\mathbf{Z}_{\mathbf{R}}\end{array}$ & $\begin{array}{c}\text { Base of the cone } \\
\mathbf{Z}_{\mathbf{S}}\end{array}$ \\
\hline [MPa] & & $Z_{R}=0,33 \times F^{0,5} \times\left(p_{r}+0,1\right)^{0,5}=\mathbf{7} \mathbf{~ m}$ & $Z_{S}=0,175 \times d=\mathbf{5 , 6}$ \\
\hline
\end{tabular}

In addition, around the outlet opening of the bleed pipe, an explosive hazardous area 1 with radius $\mathrm{R}=1 \mathrm{~m}$ has been determined, in accordance with the referenced Technical Standard [9].

For the conditions described above, a computer simulation was performed, the results of which are illustrated in Figures 3, 4 and 5.

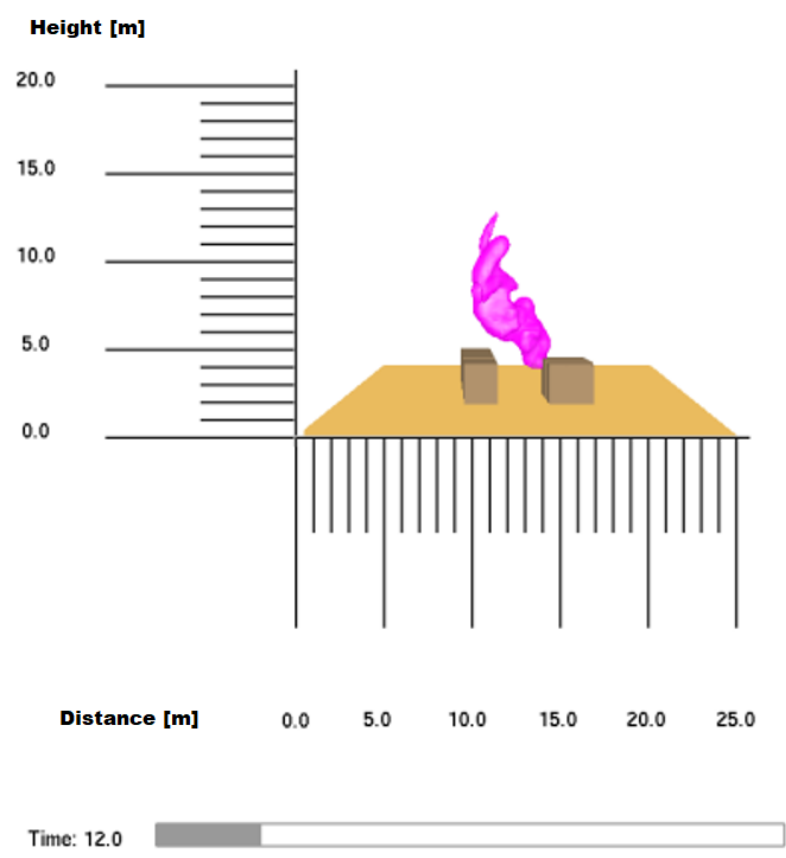

Fig. 3. Emission within 12 seconds after release. Color purple indicates natural gas which is within the limits of explosive concentrations.

The time-step is determined dynamically during calculations based on the local control volume (CV) size and velocity to ensure computational convergence. A total of about 0.9 million structured $\mathrm{CVs}$ is used, with local refinement at the jet centre to capture large gradients of velocity and methane volume fraction. Grid sensitivity tests showed that further refinement of the grid size has negligible effect on the simulation results. The simulation takes into account the wind velocity of $1.0 \mathrm{~m} / \mathrm{s}$ and direction consistent with the Windrose software for the analyzed area. 


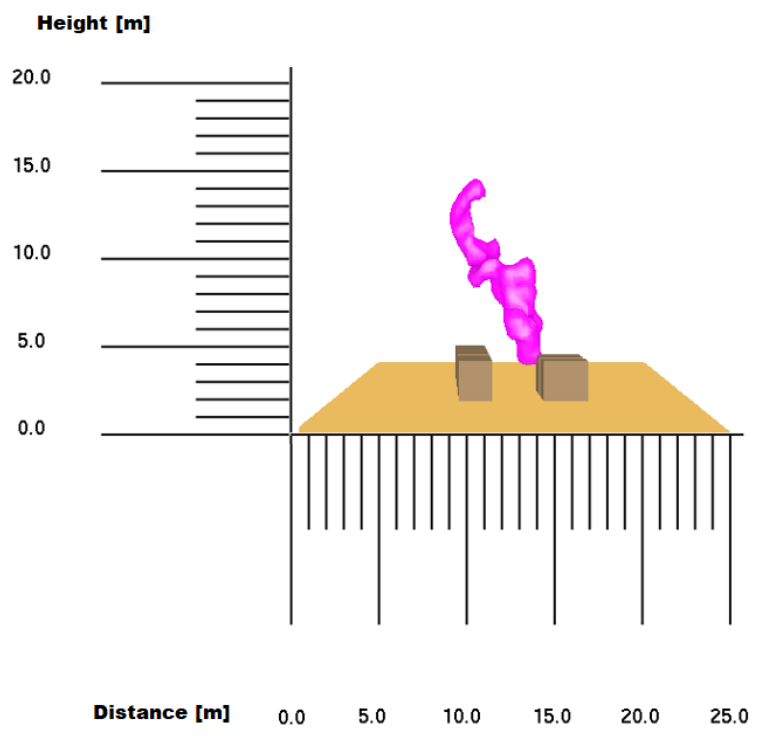

Time: 32.0

Fig. 4. Emission within 32 seconds after release.

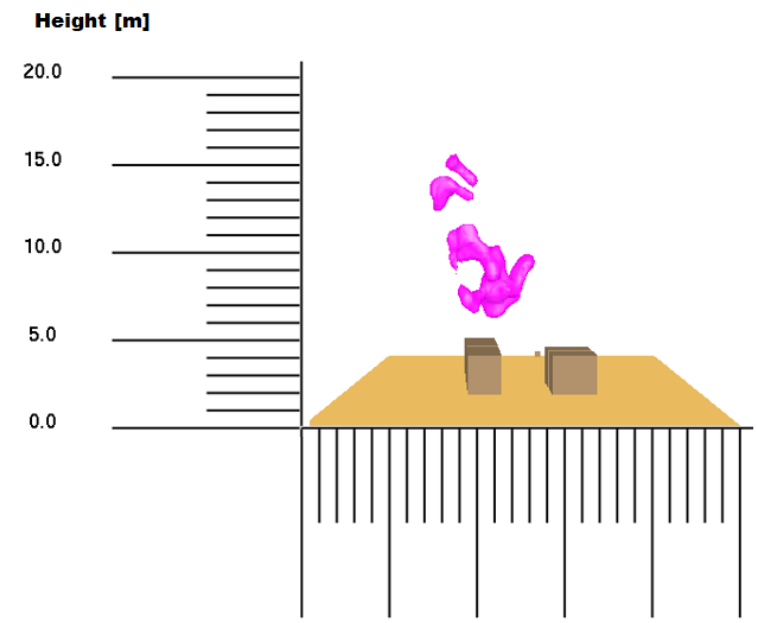

$\begin{array}{lllllll}\text { Distance [m] } & 0.0 & 5.0 & 10.0 & 15.0 & 20.0 & 25.0\end{array}$

Time: 68.0

Fig. 5. Emission within 68 seconds after release.

As can be seen from the figures above, the shape in which the explosive concentration is contained during the emission from the safety valve, differs from the theoretical 
assumptions described in the Technical Standard ST-IGG-0401:2015 [9], for which, the shape of the sphere and the base of the cone is a certain simplification.

Nevertheless, the sphere-shaped area / zone with the base of the cone includes the shape of the area / zone specified in the simulation, which suggests the correctness of its execution. The shape of the area / zone, which is illustrated by the simulation, is therefore slightly more similar to the shape of a cylinder. This conclusion coincides with the information contained in IGE/SR/25 - Safety Recommendations - Hazardous area classification of Natural Gas Instalations - The Institution of Gas Engineers [10] and the description in the article 'Potentially explosive hazardous areas for natural gas installations' published in FP (Fire Protection) No 2/14 [11]. An additional advantage of the simulation is the determination of the gas mass that stays in the atmosphere despite dispersions, which allows to determine the potential explosion force. This phenomenon is unlikely to occur in the open area, as it turns out, as natural ventilation is usually sufficient to ensure effective dispersion of the creating explosive atmosphere. An immediate ignition can lead to the gas combustion and the jetfire may form. Despite this, technical standards somehow enforce the designation of explosive hazardous areas. The designation of potentially explosive hazardous zones in open areas is dictated by particular concern for the safety of the environment and should be carried out with a view to the application of preventive measures against not only explosion but also uncontrolled ignition of natural gas and air mixtures. This wording is also justified in the case of setting minimum distances / clearances for natural gas installations from buildings and other facilities. In accordance with paragraph 40 of the Regulation of the Minister of Economy of 26 April 2013. (Journal of Laws of 4 June 2013, item 640) on technical conditions to be met by gas networks and their location [12], for gas stations the distances from buildings should be greater than the horizontal range of explosive hazardous areas established for those stations, unless otherwise provided for in this Regulation.

\section{Conclusions}

In the era of technological development and popularity of computer software, as well as increasing computing power of computers, the introduction of CFD methodology as an effective tool, helpful also in classifying explosive hazardous areas / zones, should be considered. Nowadays, no one is surprised by the use of simulations based on ALOHA, PHAST, RIZEX and other programs. Properly performed simulations of smoke objects or fire development also become useful. This makes it all the more important to improve the knowledge base on the phenomena associated with the emission of flammable liquids/ fumes /dusts /gases for the purposes of classifying explosive hazardous areas / zones. However, it should be reminded that the standard PN-EN 60079-10-1:2016-02 [3] belongs to the family of electrical standards, and the classification of areas / zones serves to indicate the correct location of Ex devices. Nevertheless, the correct location of electrical equipment, which according to the Regulation of the Ministry of the Interior and Administration dated 7 June 2010 on fire protection of buildings, and other building structures and areas (Journal of Laws No. 109, item 719) [13] are a fire protection devices ("...equipment preventing an explosion and limiting its effects ..."), should be taken into account as a fire and explosion safety element of any facility where such hazards occur. 


\section{References}

1. A. Polanczyk, P. Wawrzyniak, I. Zbicinski, Dry. Techn. 31(8), 881 (2013)

2. P. Wawrzyniak, A. Polańczyk, I. Zbicinski, M. Jaskulski, M. Podyma, J. Rabaeva, Dry. Techn. 30(15), 1720 (2012)

3. PN-EN 60079-10-1: 2016-02

4. R. Pape, K.R. Mniszewski, Computational fluid dynamics methods of calculating gas dispersion in a building or outside as a result of gas leaks (Society of Fire Protection Engineers, 2005)

5. N.L. Ryder, J.A. Sutula, CH.F. Schemel, A.J. Hamer, V.V. Brunt, J. Hazard. Mat. 115, 149 (2004)

6. J. Zhang, J. Hereid, M. Hagen, D. Bakirtzis, M.A. Delichatsios, A.G. Venetsanos, Int. J. Hydro. Energy 35/12, 6431 (2010)

7. K. McGrattan, R. McDermott, S. Hostikka, J. Floyd, M. Vanella, K. Overholt, C. Weinschenk, Fire Dynamics Simulator (Version 6.6.0) Technical Reference Guide. Volume 1: Mathematical Model, Sixth Edition (NIST Special Publication 1018-1, November 1, 2017)

8. G.P. Forney, Smokeview, A Tool for Visualizing Fire Dynamics Simulation Data. Volume I: User's Guide, Sixth Edition (NIST Special Publication 1017-1)

9. ST-IGG-0401:2015

10. IGE/SR/25 - Safety Recommendations - Hazardous area classification of Natural Gas Instalations - The Institution of Gas Engineers.

11. R. Żuczek, P. Roczek, Ochrona Przeciwpożarowa 2 (2014)

12. Regulation of the Minister of Economy of 26 April 2013 on technical conditions to be met by gas networks and their location (Journal of Laws of 4 June 2013, item 640)

13. Regulation of the Ministry of the Interior and Administration dated 7 June 2010 on fire protection of buildings, and other building structures and areas (Journal of Laws No. 109, item 719) 